Reducing progression in progressive multiple sclerosis

Jeremy Chataway

Multiple sclerosis (MS) therapeutics continues to evolve and is one of the most vibrant areas of research in the clinical neuroscience community. To the earlier relapsing ('inflammatory') stage of the disease a wide variety of agents can be applied, ranging from, injectable (betainterferons, glatiramer acetate) to oral (teriflunamide, dimethyl fumarate, fingolimod, cladribine) to monoclonal agents (natalizumab, alemtuzumab, ocrelizumab). ${ }^{1}$ Indeed in clinical practice, much time is devoted to sequencing the order of treatments and balancing effectiveness with possible side-effects, depending on the pattern of disease activity of the individual. Trials are now starting to consider induction versus escalation, combination versus single agent, and exit versus maintenance strategies. Yet despite these major advances, the problem of progression remains stubborn. Logically, the task is to prevent or delay progression using the approaches described above, or if established, to slow, stop or reverse it. Progression can be broadly characterised as inflammatory or non-inflammatory superimposed onto the primary progressive MS (PPMS) or secondary progressive MS (SPMS) classification. ${ }^{2}$ The litany and possible causes of trial failure in progressive MS in previous decades has been regularly described. ${ }^{3}$ However now set against this, published in The Lancet are the positive results of the EXPAND trial in SPMS, where there is a relative reduction in 3-month confirmed disability (CDP) by $21 \%{ }^{4}$ This is part of quartet of large phase 3 trials in progressive MS over the last 2 years, with four different drugs, split evenly between PPMS and SPMS: two positive and two negative. All of these drugs would be seen as anti-inflammatory and have come from the relapsing-remitting MS (RRMS) arena, encompassing a variety of mechanisms: sphingosine 1-phosphate (S1P) receptor modulation, anti-CD20-expressing B cell and anti-integrin- $\alpha 4$. The table outlines some topline features. ${ }^{4-7}$

At the heart of these results is the debate around inflammatory and non-inflammatory drivers of progression. The former might include $T$ and $B$ lymphocyte infiltration and $B$ lymphocyte-rich lymphoid follicles; the latter might include injury by iron and reactive oxygen species, energy failure, calcium influx and enhanced susceptibility to vascular comorbidities. ${ }^{8}$ The external markers of active inflammation are relapse and/or new MRI lesion activity. What then, extrapolating from this contemporary dataset of over 4000 trial participants are the rules we could apply to the individual patient with progressive MS, knowing that the ratio of inflammatory/non-inflammatory activity will vary in each individual and will be dynamic over time?

One burning question is whether the successful agents will have the most traction in the earlier, perhaps more active stages of progression and the effect will wane (perhaps significantly) in the later less inflammatory stages. It has been argued in PPMS that the reason for the net positive result seen in ORATORIO (ocrelizumab) compared against the negative of INFORMS (fingolimod) was that the trial cohort of the former was a more active cohort with an inflammatory T1 Gadolinium enhancing (GdE) burden at baseline of $27 \%$ vs $13 \%$. 
Moving onto trials in SPMS then we see success for siponimod (a sister drug to fingolimod) but failure for natalizumab. What does the fine dissection of the EXPAND trial expose? The 3 -month CDP was reduced from $32 \%$ to $26 \%$ across the whole trial, which had $21 \% \mathrm{GdE}$ activity at baseline. Sub-group analyses (figures 2 and $\mathrm{S}^{4}$ ) show trends in favour of more effect with more inflammatory activity and younger age, though the study was not powered to look for interactions.

This trial is instructive for other reasons. It confirms that the Expanded Disability Status Scale (EDSS), though, not sophisticated, does seem to good enough, and is unlikely to be replaced in phase 3 work in the near future, though there is clear promise for composite outcomes in terms of increased event rates. Biomarker utility is also underscored by this trial, with mean whole brain atrophy rates reduced significantly by siponimod. Whilst other potential modalities are being explored, optical coherence tomography, neurofilament light chains, and advanced MRI (eg, magnetisation transfer ratio, thalamic/spinal cord atrophy) are front runners, at present, whole brain volume looks now to be established as the phase 2/interim marker of choice in progressive MS.

Overall then for patients with progressive MS, what conclusions do these four trials and EXPAND in particular, say to us? Ocrelizumab and siponimod have overall trial effects of reducing the 3 -month CDP by $21-24 \%$ in relative terms. Modest, but a start. They hint that more effect is seen in a more inflammatory environment. They underline the historic truth that not all RRMS drugs will work in established progressive MS, though it would be fascinating to re-run INFORMS with siponimod. For the individual patient they challenge us with two paradigms, either to use these agents across the board as the standard of care continuously and longitudinally, regardless of the clinical/MRI baseline characteristics. Or, alternatively, to try and individualise the risk-benefit ratio according to rough macromeasures such as clinical and MRI findings, which may vary over time. They warn us that non-inflammatory progression is likely to be (much) harder to make an impact on, though there is a pipeline of novel agents (for example, simvastatin, ${ }^{9}$ ibudilast, ${ }^{10}$ biotin $^{11}$ ) showing phase 2 success and some starting the next stage of the journey.

A new dawn has broken, and those patients, investigators and sponsors taking part and leading this work should be congratulated, as a major health problem starts to be encircled by large, randomised and controlled studies.

\section{Conflicts of interest/Funding}

J. Chataway has received support from the Efficacy and Mechanism Evaluation Programme and Health Technology Assessment Programme (NIHR); UK Multiple Sclerosis Society and National Multiple Sclerosis Society. In the last 3 years, he has been a local principal investigator for trials in multiple sclerosis funded by Receptos, Novartis, and Biogen Idec, and has received an investigator grant from Novartis outside this work. He has taken part in advisory boards/consultancy for Roche, Merck KGaA Germany, MedDay,Biogen, and Apitope. 


\begin{tabular}{|c|c|c|c|c|}
\hline Study name & INFORMS & ORATORIO & EXPAND & ASCEND \\
\hline Drug & Fingolimod & Ocrelizumab & Siponimod & Natalizumab \\
\hline Main mechanism & $\begin{array}{l}\text { S1P receptor } \\
\text { modulation }\end{array}$ & $\begin{array}{l}\text { Anti-CD20- } \\
\text { expressing B cell }\end{array}$ & $\begin{array}{l}\text { S1P receptor } \\
\text { modulation }\end{array}$ & Anti-integrin- $\alpha 4$ \\
\hline $\begin{array}{l}\text { NCT (date of online } \\
\text { publication reference) }\end{array}$ & $\begin{array}{l}\text { NCT00731692 } \\
\left(01 / 2016^{5}\right)\end{array}$ & $\begin{array}{l}\text { NCT01194570 } \\
\left(12 / 2016^{6}\right)\end{array}$ & $\begin{array}{l}\text { NCT01665144 } \\
\left(03 / 2018^{4}\right)\end{array}$ & $\begin{array}{l}\text { NCT01416181 } \\
\left(03 / 2018^{7}\right)\end{array}$ \\
\hline PMS type & PPMS & PPMS & SPMS & SPMS \\
\hline $\mathrm{N}$ & 823 & 732 & 1651 & 887 \\
\hline $\begin{array}{l}\text { Primary outcome for } \\
\text { progression }\end{array}$ & $\begin{array}{l}\text { Composite: time } \\
\text { to 3-month CDP }\end{array}$ & $\begin{array}{l}\text { EDSS: time to 3- } \\
\text { month CDP }\end{array}$ & $\begin{array}{l}\text { EDSS: time to 3- } \\
\text { month CDP }\end{array}$ & $\begin{array}{l}\text { Composite: time } \\
\text { to 6-month CDP }\end{array}$ \\
\hline Mean age (sd) (years) & $\begin{array}{l}49 \\
(8.4)\end{array}$ & $\begin{array}{l}45 \\
\text { ( } 7.9 \text { active;8.3 } \\
\text { placebo)* }\end{array}$ & $\begin{array}{l}48 \\
\text { ( } 7.8 \text { active; } 7.9 \\
\text { placebo) }\end{array}$ & $\begin{array}{l}47 \\
\text { ( } 7.4 \text { active; } 7.8 \\
\text { placebo) }\end{array}$ \\
\hline $\begin{array}{l}\text { Mean duration of } \\
\text { progression (sd) (years) }\end{array}$ & $6(2.4)$ & $\begin{array}{l}7 \text { (4.0 active; } 3.6 \\
\text { placebo)* }\end{array}$ & $\begin{array}{l}4 \text { ( } 3.6 \text { active; } 3.3 \\
\text { placebo) }\end{array}$ & $\begin{array}{l}5 \text { (3.0 active; } 3.7 \\
\text { placebo) }\end{array}$ \\
\hline $\begin{array}{l}\text { Patients with baseline T1 } \\
\text { GdE lesions (absolute } \\
\text { number) }\end{array}$ & $13 \%(110)$ & $27 \%(193)$ & $21 \%(351)$ & $24 \%(210)$ \\
\hline Placebo vs active CDP & $\begin{array}{l}69 \%(338 / 487) \text { vs } \\
69 \%(232 / 336) \\
{[80 \% \text { vs } 77 \% \mathrm{KM}} \\
\text { estimate] }\end{array}$ & $\begin{array}{l}39 \%(96 / 244) \text { vs } \\
33 \%(160 / 487)\end{array}$ & $\begin{array}{l}32 \%(173 / 545) \text { vs } \\
26 \%(288 / 1096)\end{array}$ & $\begin{array}{l}\text { 48\% (214/448) vs } \\
44 \%(195 / 439)\end{array}$ \\
\hline $\begin{array}{l}\text { Primary outcome Hazard } \\
\text { ratio/Odds ratio }(95 \% \mathrm{Cl})\end{array}$ & $\begin{array}{l}\text { HR } 0.95(0.80- \\
1.12)\end{array}$ & $\begin{array}{l}\text { HR } 0.76(0.59- \\
0.98)\end{array}$ & $\begin{array}{l}\text { HR } 0.79(0.65- \\
0.95)\end{array}$ & $\begin{array}{l}\text { OR } 0.86(0.66- \\
1.13)\end{array}$ \\
\hline Primary outcome result & negative & positive & positive & negative \\
\hline
\end{tabular}

PMS=Progressive MS; PPMS=Primary progressive MS; SPMS=Secondary progressive MS; $\mathrm{CDP}=$ confirmed disability progression; EDSS=Expanded Disability Status Scale; Composite: one or more of progression in EDSS, 25 Foot Timed-Walk Test, Nine-Hole Peg Test; T1GdE=T1-Gadoliniumenhancing; KM=Kaplan-Meier; ${ }^{*}$ mean total cohort sd not calculated, so both active and placebo given.

\section{References}

1.Comi G, Radaelli M, Sorensen PS. Evolving concepts in the treatment of relapsing multiple sclerosis. Lancet 2017;389:1347-56.

2.Lublin FD, Reingold SC, Cohen JA, et al. Defining the clinical course of multiple sclerosis: the 2013 revisions. Neurology 2014; 83:278-86. 
3.Ontaneda D, Fox RJ, Chataway J. Clinical trials in progressive multiple sclerosis: lessons learned and future perspectives. Lancet Neurol 2015;14:208-23.

4.Kappos L, Bar-Or A, Cree BAC, et al, for the EXPAND Clinical Investigators. Siponimod versus placebo in secondary progressive multiple sclerosis (EXPAND): a double-blind, randomised, phase 3 study. Lancet 2018; published online March 22. http://dx.doi.org/10.1016/S0140- 6736(18)30475-6.

5.Lublin F, Miller DH, Freedman MS, et al. Oral fingolimod in primary progressive multiple sclerosis (INFORMS): a phase 3, randomised, double-blind, placebo-controlled trial. Lancet 2016;387:107584.

6.Montalban X HB, Rammohan K, Giovannoni $\mathrm{G}$, et al, on behalf of the ORATORIO Clinical Investigators. Ocrelizumab versus placebo in in primary progressive multiple sclerosis. $N$ Engl J Med. 2017;376:209-20.

7.Kapoor R, Ho P-R, Campbell N, et al. Effect of natalizumab on disease progression in secondary progressive multiple sclerosis (ASCEND): a phase 3, randomised, double-blind, placebo-controlled trial with an open-label extension. Lancet Neurol 2018; published online March 12. http://dx.doi.org/10.1016/S1474-4422(18)30069-3.

8. Lassmann H. Targets of therapy in progressive MS. MSJ 2017;23:1593-99.

9.Chataway J, Schuerer N, Alsanousi A, et al. Effect of high-dose simvastatin on brain atrophy and disability in secondary progressive multiple sclerosis (MS-STAT): a randomised, placebo-controlled, phase 2 trial. Lancet 2014;383:2213-21.

10.Fox RJ, Coffey CS, Cudkowicz ME, et al. Design, rationale, and baseline characteristics of the randomized double-blind phase II clinical trial of ibudilast in progressive multiple sclerosis. Contemp Clin Trials 2016;50:166-77.

11.Tourbah A, Lebrun-Frenay C, Edan G, et al. MD1003 (high-dose biotin) for the treatment of progressive multiple sclerosis: A randomised, double-blind, placebo-controlled study. MSJ 2016;13:1719-31. 